\title{
Quantifying the Scope for Efficiency Defense in Merger Control: The Werden-Froeb-Index*
}

\author{
Marie Goppelsroeder ${ }^{\dagger}$ Maarten Pieter Schinkel ${ }^{\ddagger}$ Jan Tuinstra ${ }^{\S}$ \\ July 2006
}

\begin{abstract}
In both US and EU merger control, merger-specific efficiencies are recognized as a possible defense for horizontal mergers that raise competition concerns. We introduce the Werden-Froeb-index (WFI) to assist in evaluating these efficiencies. The index measures the average reduction in marginal costs required to restore pre-merger equilibrium prices and quantities after the merger is consummated. It has low information requirements and can deal with any number of firms in price- or quantity-competition merging fully or partially, and a large class of demand and cost functions. We show how the WFI complements Phase I merger inquiries as a screening mechanism.
\end{abstract}

Keywords: Merger control, efficiency defense, index, HHI.

JEL-codes: L100, L400, C430.

\section{Introduction}

When the analysis is restricted ceteris paribus to competition effects, economic theory predicts unambiguously that (partial) horizontal mergers lead to anticompetitive effects and consumer detriment. ${ }^{1}$ In light of this, competition authorities around

${ }^{*}$ We thank Luis Cabral, Stephen Davies, Tomaso Duso, Franklin Fisher, Sven-Olof Fridolfsson, Luke Froeb, Morten Hviid, Marc Ivaldi, Bruce Lyons, Rainer Nitsche, Frank Verboven, Gregory Werden and participants to the 2006 IIOC meeting in Boston and the 3rd CEPR Applied IO Summer School, 2006 in Funchal, Madeira for discussions and comments to earlier versions of this paper. Valuable research assistance was provided by Tashi Erdmann and Benjamin Kemper. Opinions and errors remain ours.

${ }^{\dagger}$ Graduate Institute of International Studies, Geneva, Switzerland. Marie Goppelsroeder gratefully acknowledges financial support by the CEPR RTN "Competition in International Markets".

${ }^{\ddagger}$ Department of Economics and ACLE, Universiteit van Amsterdam. Address: Roetersstraat 11, 1018 WB Amsterdam, The Netherlands, m.p.schinkel@uva.nl.

${ }^{\S}$ Department of Quantitative Economics and CeNDEF, Universiteit van Amsterdam.

${ }^{1}$ See Perry and Porter (1985), Davidson and Deneckere (1985) and Reynolds and Snapp (1986). 
the world follow them closely. Yet, the market dynamics of consolidations, hostile take-overs, friendly (partial) acquisitions and mergers can also generate important synergies. $^{2}$ Proper merger policy weighs such merger specific efficiencies against the anticompetitive effects of the merger.

In the last decade merger control in both US and EU has opened up to efficiency arguments. $^{3}$ They have been admitted in cases to supplement market concentration analyses based on the Hirschmann-Herfindahl-index (HHI). The US guidelines, revised in 1997 on this point, read:

"[T]he merging firms must substantiate efficiency claims so that the Agency can verify by reasonable means the likelihood and magnitude of each asserted efficiency, how and when each would be achieved (and any costs of doing so), how each would enhance the merged firm's ability and incentive to compete, and why each would be merger-specific. Efficiency claims will not be considered if they are vague or speculative or otherwise cannot be verified by reasonable means." (US Department of Justice and US Federal Trade Commission, 1997, Section 4)

Similarly, the following section was adopted into the 2004 European merger guidelines:

"The Commission considers any substantiated efficiency claim in the overall assessment of the merger. It may decide that, as a consequence of the efficiencies that the merger brings about, there are no grounds for declaring the merger incompatible with the common market pursuant to Article 2(3) of the Merger Regulation. This will be the case when the Commission is in a position to conclude on the basis of sufficient evidence that the efficiencies generated by the merger are likely to enhance the ability and incentive of the merged entity to act pro-competitively for the benefit of consumers, thereby counteracting the adverse effects on competition which the merger might otherwise have." (Commission of the European Communities, 2004, Paragraph 77)

As a result of the ex ante nature of merger control, the balancing of competition and efficiency effects is complicated in practice. Efficiencies in particular are "easy to promise, yet may be difficult to deliver." 4 This makes the evaluation of notified mergers costly, requiring considerable resources, time, and expertise. Competition authorities increasingly employ sophisticated economic analysis, including computer

\footnotetext{
${ }^{2}$ See Williamson (1968) and Farrell and Shapiro (1990; 2001).

${ }^{3}$ See Kolasky and Dick (2003) on the evolution of US merger control and Lyons (2004) on that in the EU.

${ }^{4}$ White (1987), p.18. Fisher (1987) adds that: "Such claims are easily made, and, I think, often too easily believed." (op.cit., p.36). See also Lagerloef and Heidhues (2005) and Fabrizi and Lippert (2006).
} 
simulation techniques, to assist in the weighing of the various effects of a merger. ${ }^{5}$ Combining structural oligopoly models with econometric specifications to quantify predicted market reactions following a merger, these methods advance merger control. Yet, the approach also has limitations. The analyses often are difficult, expensive and time-consuming to perform, even when based on static games and employing only a limited number of variations in demand and cost functions. In addition to these enforcement costs, allowing efficiency argument invites rent seeking from firms. Moreover, the studies often remain confidential and undisclosed, which forfeits their potential benefit of making merger decisions more transparent. ${ }^{6}$

In this paper, we propose an alternative method to assess horizontal merger efficiencies, introducing the Werden-Froeb-index (WFI). The WFI is based on Compensating Marginal Cost Reductions (CMCRs), a concept developed in Werden (1996) and Froeb and Werden (1998) and generalized in this paper. The CMCR of each commodity involved in the merger is the reduction in the commodity's (marginal) production costs after the merger that is minimally required to obtain the status quo in terms of quantities and prices that exists prior to the merger. ${ }^{7}$ The WFI is a weighted average of generalized CMCRs, with the weights being the shares in total production of the merged firm. It is a measure of the relative savings in total (marginal) cost of producing the commodities involved in the merger, that is required to restore pre-merger equilibrium values.

The paper is organized as follows. In the next section, generalized CMCRs are established for any number of differentiated goods and firms, of which two or more merge, fully or partially, when competition is either on quantities (Cournot) or on prices (Bertrand). Section 3 defines the Werden-Froeb-index. Section 4 sets out its information requirements. Section 5 discusses how to implement the WFI practically in merger control, supplementing standard HHI-analysis. Several numerical examples of mergers in a representative market illustrate the power of the measure. Section 6 concludes. A short routine in MATLAB ${ }^{\circledR}$ for calculating the WFI in a typical merger is given in the appendix.

\section{Compensating Marginal Cost Reductions}

The conceptual idea of compensating marginal cost reductions is to establish the efficiency gains that minimally need to materialize in order to off-set a merger's competition-reducing effects. CMCRs thereby replicate the market status quo in

\footnotetext{
${ }^{5}$ See Werden and Froeb (1996; 2006), Werden (1997), and Bergeijk and Kloosterhuis (2005).

${ }^{6}$ See Goppelsroeder and Schinkel (2005) for a more extensive critique.

${ }^{7}$ Independently, Verboven et al. (1999), Röller et al. (2001) and Stennek and Verboven (2003) developed a similar concept, which they call 'Minimum Required Efficiencies' (MREs), in reports for the European Commission. MREs are defined as the ratio of the anticompetitive price increase as a result of the merger over the rate at which the (claimed) actual merger-specific cost savings are passed on to the consumers.
} 
terms of prices and quantities. Consumers would be indifferent between allowing or blocking the merger, if these cost savings would indeed result from the merging parties integrating their business. ${ }^{8}$ In any given industry, the CMCR commodity values depend on specifics like the nature of the (marginal) production costs, commodity characteristics, and the type of market competition. Gregory Werden and Luke Froeb developed the concept for a limited number of common settings, involving constant marginal costs and two firms merging fully into one. Werden (1996) models Bertrand competition among differentiated substitute commodities. Froeb and Werden (1998) considers Cournot competition among producers of a homogenous good that differ only in their share of the market. ${ }^{9}$ In this section, we generalize these contributions in one integrated setup. ${ }^{10}$

Note that the concept of CMCRs abstracts from any post-merger reallocation of production to the more efficient divisions of the merged firm. Although possibly restrictive in the special case of a single homogenous good, it is this assumption that makes the concept generally practical. ${ }^{11}$ Furthermore, in the following we abstract from at least two important effects of mergers that involve differentiated commodities. The first is that the integrated firm may have a post-merger incentive to reconsider its portfolio of products, repositioning them by adjusting their differentiation, extending or possibly discontinuing some of its product lines. ${ }^{12}$ We assume these effects away by considering a fixed product spectrum. Second, we assume that the mode of competition does not change as a result of the merger.

Consider a market in which $n$ (possibly slightly) differentiated products are produced and supplied by $K \leq n$ different firms. Each commodity is produced by only one firm, but some firms may produce several commodities. ${ }^{13}$ In particular, we assume that firm $k$ produces $m_{k}$ different commodities, with $\sum_{k=1}^{K} m_{k}=n$. Without loss of generality, we number commodities such that the first $m_{1}$ commodities

\footnotetext{
${ }^{8}$ This approach therefore is in line with the consumer welfare standard, as discussed further in Section 5. It does not recognize efficiency defense arguments that, although possibly enhancing total welfare, are not passed on to a sufficient extent to consumers, such as merger-specific reductions in fixed cost (overhead). See Farrell and Shapiro (2001).

${ }^{9}$ Stennek and Verboven (2003), Section 4 analyzes these same basic models. In addition, it considers a merger between two firms out of three, competing on prices in a homogenous commodity produced against different constant marginal cost levels.

${ }^{10}$ In the following, we derive CMCRs in absolute value. In Werden (1996), as well as in Stennek and Verboven (2003), the required marginal cost reductions, and MREs, are expressed relative to original marginal cost levels. In Froeb and Werden (1998), a "proportionate" CMCR is presented that is a special case of the WFI-see footnote 23 in Section 3.

${ }^{11}$ Stennek and Verboven (2003) include this post-merger cost-minimizing reallocation of production in their presentation of the MREs for the most efficient firm in the merger only. The issue is discussed further in Section 5.

${ }^{12}$ Gandhi et al. (2005) develop simulation analyses in which product variety increases with concentration. Berry and Waldfogel (2001) find evidence to the effect in radio broadcasting.

${ }^{13} \mathrm{We}$ introduce this setup for notational convenience. One way to interpret it is as commodities being (slightly) firm-specific. Yet, for both Cournot and Bertrand competition, in the two subsections below, we also consider the special case of purely homogenous commodities.
} 
are produced by firm 1 , commodities $m_{1}+1, \ldots, m_{1}+m_{2}$ by firm 2 , commodities $m_{1}+m_{2}+1, \ldots, m_{1}+m_{2}+m_{3}$ by firm 3 and so on. Note that this numbering can always be done in such a way that the first $l$ firms are the merging firms. Also define $n_{k}=\sum_{j=1}^{k} m_{k}$. Obviously, $n_{0}=0$ and $n_{K}=n$.

Demand for product $i$ is given by the demand function $Q_{i}(\mathbf{p})=Q_{i}\left(p_{1}, \ldots, p_{n}\right)$, where $p_{j}>0$ is the price of the $j$ 'th product, and $\mathbf{p} \in \mathbb{R}_{++}^{n}$ is the full price vector. The function $Q_{i}(\mathbf{p})$ is assumed to be positive, continuous and twice continuously differentiable everywhere. Moreover, we assume $\frac{\partial Q_{i}(\mathbf{p})}{\partial p_{i}} \leq 0$. Commodity $i$ is called a substitute for commodity $j$ at $\mathbf{p}$ if $\frac{\partial Q_{i}(\mathbf{p})}{\partial p_{j}}>0$. Mergers may also involve complementary goods previously sold by competing firms - commodities $i$ and $j$ are complements

at $\mathbf{p}$, if $\frac{\partial Q_{i}(\mathbf{p})}{\partial p_{j}}<0$ - in which case the merger may, in fact, decrease prices. Assuming the conditions for the inverse function theorem to hold, the inverse demand functions exist as the prices that clear the market at the quantities produced. Denote the inverse demand function for product $i$ by $P_{i}(\mathbf{q})=P_{i}\left(q_{1}, \ldots, q_{n}\right)$ and assume that they are also positive, continuous and twice continuously differentiable.

The costs for firm $k$ of producing the production bundle $\left(q_{n_{k-1}+1}, \ldots, q_{n_{k}}\right)$ are given by a cost function $C_{k}\left(q_{n_{k-1}+1}, \ldots, q_{n_{k}}\right)=C_{k}\left(\mathbf{q}_{k}\right)$, which is strictly positive, increasing in its arguments, and twice continuously differentiable. By $c_{i}\left(\mathbf{q}_{k}\right)$ we will denote the marginal costs associated to product $i$ (where $n_{k-1}+1 \leq i \leq n_{k}$ ). Without making any more specific assumptions on the cost functions, we will assume that all equilibria correspond to solutions of the first-order conditions and that second-order conditions for a global maximum are always satisfied. After the first $l$ firms out of the pool of $K$ have merged, the merged entity subsequently faces cost function $\widetilde{C}\left(q_{1}, \ldots, q_{n_{l}}\right)=\widetilde{C}\left(\mathbf{q}_{1}, \ldots, \mathbf{q}_{l}\right)$. Again, this cost function is strictly positive, nondecreasing in its arguments and twice continuously differentiable. Marginal costs with respect to the production of commodity $i\left(1 \leq i \leq n_{l}\right)$ are denoted by $\widetilde{c}_{i}\left(q_{1}, \ldots, q_{n_{l}}\right)$.

In the following two subsections, we derive CMRCs as the absolute marginal costs reductions required to replicate the pre-merger equilibrium in the post-merger market for fully integrating firms in Cournot and Bertrand competition respectively. The section closes with a characterization of CMCRs for partial acquisitions.

\subsection{CMCRs in Cournot Competition}

Suppose that firms use quantities as their strategic variables and prices adjust in such a way that markets clear. For illustrative purposes, first consider the special case where, before the full merger, each firm produces only one product variety - that is $K=n, m_{k}=1$ and $n_{k}=k$ for every $k$. Firm $i$, producing commodity $i$, then chooses $q_{i}$ by profit maximization

$$
\max _{q_{i}} P_{i}(\mathbf{q}) q_{i}-C_{i}\left(q_{i}\right)
$$


The first-order condition for this problem is

$$
P_{i}(\mathbf{q})+q_{i} \frac{\partial P_{i}(\mathbf{q})}{\partial q_{i}}-c_{i}\left(q_{i}\right)=0
$$

for firm $i$. The Cournot-Nash equilibrium quantities $\mathbf{q}^{*}$ are a vector $\left(q_{1}^{*}, \ldots, q_{n}^{*}\right)$, such that (1) is satisfied for every firm $i$. The associated equilibrium prices are given by $p_{i}^{*}=P_{i}\left(\mathbf{q}^{*}\right)$, for $i=1, \ldots, n$.

Next, consider the effect of a merger between the first $l$ firms. The merged entity's profit maximization problem then becomes

$$
\max _{q_{1}, \ldots, q_{l}} P_{1}(\mathbf{q}) q_{1}+P_{2}(\mathbf{q}) q_{2}+\ldots+P_{l}(\mathbf{q}) q_{l}-\widetilde{C}\left(q_{1}, q_{2}, \ldots, q_{l}\right),
$$

from which the system of first-order conditions follows as:

$$
\begin{array}{cc}
P_{1}(\mathbf{q})+q_{1} \frac{\partial P_{1}(\mathbf{q})}{\partial q_{1}}+q_{2} \frac{\partial P_{2}(\mathbf{q})}{\partial q_{1}}+\ldots+q_{l} \frac{\partial P_{l}(\mathbf{q})}{\partial q_{1}}-\widetilde{c}_{1}\left(q_{1}, \ldots, q_{l}\right)= & 0 \\
P_{2}(\mathbf{q})+q_{1} \frac{\partial P_{1}(\mathbf{q})}{\partial q_{2}}+q_{2} \frac{\partial P_{2}(\mathbf{q})}{\partial q_{2}}+\ldots+q_{l} \frac{\partial P_{l}(\mathbf{q})}{\partial q_{2}}-\widetilde{c}_{2}\left(q_{1}, \ldots, q_{l}\right)= & 0 \\
P_{l}(\mathbf{q})+q_{1} \frac{\partial P_{1}(\mathbf{q})}{\partial q_{l}}+q_{2} \frac{\partial P_{2}(\mathbf{q})}{\partial q_{l}}+\ldots+q_{l} \frac{\partial P_{l}(\mathbf{q})}{\partial q_{l}}-\widetilde{c}_{l}\left(q_{1}, \ldots, q_{l}\right)= & \vdots
\end{array}
$$

for the first $l$ commodities. Together with conditions (1) for the firms $l+1$ to $n$ which remain outside the merger, the solution to the post-merger first-order conditions defines the Cournot-Nash equilibrium $\left(\mathbf{q}^{* *}, \mathbf{p}^{* *}\right)$.

Typically, production levels for both the merged firms $(k=1, \ldots, l)$ and the independent firms $(k=l+1, \ldots, n)$ will be different from the pre-merger Cournot-Nash equilibrium levels. However, for given quantities $\mathbf{q}$ and associated prices $\mathbf{p}$ given by $p_{i}=P_{i}(\mathbf{q})$, we can explicitly determine marginal costs $\widetilde{c}_{1}, \widetilde{c}_{2}$, up to $\widetilde{c}_{l}$ such that the post-merger first-order conditions $(2)$ are satisfied for those chosen quantities. The post-merger first-order conditions are thus employed to endogenously determine the marginal cost functions $c_{i}$ that result in a specific output vector q. For an arbitrary output vector $\mathbf{q}$, this is generally problematic. It requires a full understanding of the inverse demand functions at these quantities. Moreover, the first-order conditions for the other firms also change for $\mathbf{q} \neq \mathbf{q}^{*}$. The CMCR concept circumvents these difficulties by asking for which values of $\widetilde{c}_{i}$ the post-merger Cournot-Nash equilibrium quantities $\mathbf{q}^{* *}$ are exactly equal to the pre-merger Cournot-Nash equilibrium quantities $\mathbf{q}^{*}$. The benefit of this status quo approach is that the first-order conditions of the nonmerging firms remain the same and can therefore be disregarded in the analysis.

The necessary absolute marginal cost reductions for each product $i$ to exactly reproduce pre-merger quantities and market prices after the merger follow from com- 
bining conditions (1) and (2), as follows

$$
\begin{aligned}
\triangle c_{i} & \equiv c_{i}\left(q_{i}^{*}\right)-\widetilde{c}_{i}\left(q_{1}^{*}, \ldots, q_{l}^{*}\right) \\
& =\left(P_{i}\left(\mathbf{q}^{*}\right)-\widetilde{c}_{i}\left(q_{1}^{*}, \ldots, q_{l}^{*}\right)\right)-\left(P_{i}\left(\mathbf{q}^{*}\right)-c_{i}\left(q_{i}^{*}\right)\right) \\
& =-\left[q_{1}^{*} \frac{\partial P_{1}\left(\mathbf{q}^{*}\right)}{\partial q_{i}}+\ldots+q_{i-1}^{*} \frac{\partial P_{i-1}\left(\mathbf{q}^{*}\right)}{\partial q_{i}}+q_{i+1}^{*} \frac{\partial P_{i+1}\left(\mathbf{q}^{*}\right)}{\partial q_{i}}+\ldots+q_{l}^{*} \frac{\partial P_{l}\left(\mathbf{q}^{*}\right)}{\partial q_{i}}\right] \\
& =-\sum_{j \neq i}^{l} q_{j}^{*} \frac{\partial P_{j}\left(\mathbf{q}^{*}\right)}{\partial q_{i}} .
\end{aligned}
$$

Note that if all commodities involved in the merger are substitutes, the necessary cost reduction is positive, i.e., $\Delta c_{i}>0$. If all involved commodities are complements, $\triangle c_{i}<0$. When there is a mixed bundle of substitutes and complements involved in the merger, the signs of $\triangle c_{i}$ are ambiguous. ${ }^{14}$ Finally note that the values of $\triangle c_{i}$ are uniquely determined at the status quo equilibrium, because each commodity's total output remains the same. We need not put any restrictions on the shape of the post-merger cost functions outside equilibrium. ${ }^{15}$

Next, we generalize the analysis to cover mergers of any arbitrary number of firms $l$ that each produce an arbitrary number of varieties $m_{k}$, with $k=1, \ldots, l$. Before the merger, firm $k$ chooses quantities $q_{n_{k-1}+1}, \ldots, q_{n_{k}}$ by solving

$$
\max _{q_{n_{k-1}+1}, \ldots, q_{n_{k}}} \sum_{j=n_{k-1}+1}^{n_{k}} q_{j} P_{j}(\mathbf{q})-C_{k}\left(\mathbf{q}_{k}\right)
$$

which returns first-order conditions

$$
P_{i}(\mathbf{q})+\sum_{j=n_{k-1}+1}^{n_{k}} q_{j} \frac{\partial P_{j}(\mathbf{q})}{\partial q_{i}}-c_{i}\left(\mathbf{q}_{k}\right)=0 \quad \text { for } i=n_{k-1}+1, \ldots, n_{k} .
$$

There is a set of such first-order conditions for every merging firm.

\footnotetext{
${ }^{14}$ Note also that the necessary efficiencies might be so large that the post-merger marginal costs need to fall below zero, in which case $\Delta c_{i}>c_{i}$. We do not a priori rule out this (impossible) requirement, since the WFI deals with it quite naturally, as explained in Section 3.

${ }^{15}$ Some intuition for the specification of these CMCRs follows from considering total revenue of the merged firm, $\widetilde{R}(\mathbf{q})=\sum_{j=1}^{l} q_{j} P_{j}(\mathbf{q})$, and revenue of firm $i$ before the merger, which is $R_{i}(\mathbf{q})=q_{i} P_{i}(\mathbf{q})$. The absolute CMCR for product $i$ can be written as

$$
\triangle c_{i}=M R_{i i}\left(\mathbf{q}^{*}\right)-\widetilde{M R}_{i}\left(\mathbf{q}^{*}\right),
$$

in which $\widetilde{M R}_{i}(\mathbf{q})=\frac{\partial \widetilde{R}(\mathbf{q})}{\partial q_{i}}$ and $M R_{i i}(\mathbf{q})=\frac{\partial R_{i}(\mathbf{q})}{\partial q_{i}}$ are the associated marginal revenues. Hence, in order to assure that post-merger quantities equal pre-merger levels, the marginal cost reduction should exactly outbalance the reduction in marginal revenue from an increase in producing more of product $i$. These reductions in marginal revenue are due to the fact that the negative spill-over effects of an increase of $q_{i}$ on prices of the other commodities is internalized, which typically reduces production and increases prices.
} 
It is convenient to employ some matrix notation from now onwards. Let the following $m_{j} \times m_{i}$ matrix collect quantity effects of the products sold by firms $i$ and $j$ :

$$
\mathbf{P}_{i j}=\left(\begin{array}{cccc}
\frac{\partial P_{n_{i-1}+1}(\mathbf{q})}{\partial q_{n_{j-1}+1}} & \frac{\partial P_{n_{i-1}+2}(\mathbf{q})}{\partial q_{n_{j-1}+1}} & \cdots & \frac{\partial P_{n_{i}}(\mathbf{q})}{\partial q_{n_{j-1}+1}} \\
\frac{\partial P_{n_{i-1}+1}(\mathbf{q})}{\partial q_{n_{j-1}+2}} & \frac{\partial P_{n_{i-1}+2}(\mathbf{q})}{\partial q_{n_{j-1}+2}} & \cdots & \frac{\partial P_{n_{i}}(\mathbf{q})}{\partial q_{n_{j-1}+2}} \\
\vdots & \vdots & \ddots & \vdots \\
\frac{\partial P_{n_{i-1}+1}(\mathbf{q})}{\partial q_{n_{j}}} & \frac{\partial P_{n_{i-1}+2}(\mathbf{q})}{\partial q_{n_{j}}} & \cdots & \frac{\partial P_{n_{i}}(\mathbf{q})}{\partial q_{n_{j}}}
\end{array}\right)
$$

This matrix is the transpose of the Jacobian matrix of the inverse demand functions of the products supplied by firm $i$, or $P_{n_{i-1}+1}(\mathbf{q}), \ldots, P_{n_{i}}(\mathbf{q})$, with respect to the quantities of the commodities produced by firm $j$, that is, $q_{n_{j-1}+1}, \ldots, q_{n_{j}}$. Also denote by $\mathbf{q}^{\left(n_{l}\right)}=\left(q_{1}, \ldots, q_{n_{l}}\right)^{\prime}$ the vector of quantities of the commodities sold by the merging firms, by $\mathbf{p}^{\left(n_{l}\right)}=\left(p_{1}, \ldots, p_{n_{l}}\right)^{\prime}$ the vector of corresponding prices, and by $\mathbf{c}^{\left(n_{l}\right)}=\left(c_{1}, \ldots, c_{n_{l}}\right)^{\prime}$ the vector of relevant marginal costs. The pre-merger first-order conditions (5) for all merging firms can now concisely be written as

$$
\mathbf{p}^{\left(n_{l}\right)}+\mathbf{P}_{0} \mathbf{q}^{\left(n_{l}\right)}-\mathbf{c}^{\left(n_{l}\right)}=\mathbf{0}
$$

in which

$$
\mathbf{P}_{0}=\left(\begin{array}{cccc}
\mathbf{P}_{11} & \mathbf{0} & \cdots & \mathbf{0} \\
\mathbf{0} & \mathbf{P}_{22} & & \vdots \\
\vdots & & \ddots & \\
\mathbf{0} & \cdots & & \mathbf{P}_{l l}
\end{array}\right)
$$

collects the quantity effects of all the products involved in the merger.

We use a similar notation for the post-merger situation. The first-order conditions for the merged entity read

$$
P_{i}(\mathbf{q})+\sum_{j=1}^{n_{l}} q_{j} \frac{\partial P_{j}(\mathbf{q})}{\partial q_{i}}-\widetilde{c}_{i}\left(\mathbf{q}^{\left(n_{l}\right)}\right)=0, \quad \text { for } i=1, \ldots, n_{l},
$$

which can be summarized as

$$
\mathbf{p}^{\left(n_{l}\right)}+\mathbf{P}_{1} \mathbf{q}^{\left(n_{l}\right)}-\widetilde{\mathbf{c}}^{\left(n_{l}\right)}=\mathbf{0}
$$

Here

$$
\mathbf{P}_{1}=\left(\begin{array}{cccc}
\mathbf{P}_{11} & \mathbf{P}_{21} & \cdots & \mathbf{P}_{l 1} \\
\mathbf{P}_{12} & \mathbf{P}_{22} & & \vdots \\
\vdots & & \ddots & \\
\mathbf{P}_{1 l} & \cdots & & \mathbf{P}_{l l}
\end{array}\right)
$$

is the transpose of the Jacobian of the inverse demand function of all merging firms with respect to the quantities of all commodities they supply. This matrix collects all the post-merger quantity effects. 
The vector of CMCRs then compactly follows as - with subscript ' $\mathrm{C}$ ' referring to Cournot competition:

$$
\triangle \mathbf{c}_{C}=\mathbf{c}^{\left(n_{l}\right)}-\widetilde{\mathbf{c}}^{\left(n_{l}\right)}=\left(\mathbf{P}_{0}-\mathbf{P}_{1}\right) \mathbf{q}^{\left(n_{l}\right)}
$$

in which

$$
\mathbf{P}_{0}-\mathbf{P}_{1}=\left(\begin{array}{cccc}
\mathbf{0} & -\mathbf{P}_{21} & \cdots & -\mathbf{P}_{l 1} \\
-\mathbf{P}_{12} & \mathbf{0} & & \vdots \\
\vdots & & \ddots & \\
-\mathbf{P}_{1 l} & \cdots & & \mathbf{0}
\end{array}\right)
$$

compares pre- and post-merger quantity effects at the status quo. ${ }^{16}$

The analysis specializes straightforwardly to the case of homogenous commodities and different market shares. Homogeneity implies a single inverse demand function, $P\left(q_{1}, \ldots, q_{n}\right)=P\left(q_{1}+\ldots+q_{n}\right)$. Hence, $\frac{\partial P(\mathbf{q})}{\partial q_{i}}=P^{\prime}(\mathbf{q})$ for all $i$. Furthermore, the marginal costs post-merger must be equal for 'each' merged product. Moreover, from (2) it follows immediately that for each merging firm $i$ it must be that $\widetilde{c}_{i}=\widetilde{c}=$ $P(\mathbf{q})+P^{\prime}(\mathbf{q}) \sum_{j=1}^{l} q_{j}$, where $l$ is the number of merging firms. It follows then from equation (3) that the compensating reduction in marginal costs for firm $i$ is given by

$$
\triangle c_{C i}=-P^{\prime}\left(\mathbf{q}^{*}\right) \sum_{j=1, j \neq i}^{l} q_{j}^{*} .
$$

Note that our setup can deal with any combination of differentiated and homogeneous commodities as well.

\subsection{CMCRs in Bertrand Competition}

If firms strategically set prices rather than quantities, we can determine the CMCRs along lines similar to the Cournot case. Consider the general case of a pool of firms each producing one or more differentiated goods at varying costs, in which $l$ firms merge. Prior to the merger, firm $k$ chooses prices $\left(p_{n_{k-1}+1}, \ldots, p_{n_{k}}\right)$ in order to solve

$$
\max _{p_{n_{k-1}+1}, \ldots, p_{n_{k}}} \sum_{j=n_{k-1}+1}^{n_{k}} p_{j} Q_{j}(\mathbf{p})-C_{k}\left(Q_{n_{k-1}+1}(\mathbf{p}), \ldots, Q_{n_{k}}(\mathbf{p})\right),
$$

${ }^{16}$ The absolute CMCRs in (9) have an interpretation similar to those in (4). Denote by $R^{\left(n_{k}\right)}(\mathbf{q})=$ $\sum_{i=n_{k-1}+1}^{n_{k}} q_{i} P_{i}(\mathbf{q})$ and $\widetilde{R}(\mathbf{q})=\sum_{k=1}^{l} R^{\left(n_{k}\right)}(\mathbf{q})=\sum_{i=1}^{n_{l}} q_{i} P_{i}(\mathbf{q})$ the pre-merger revenue of the $k^{\prime}$ th firm and the post-merger revenue of the merged firm, respectively. The compensating marginal cost reduction for a product $i$ which was produced by firm $k$ before the merger (that is, $n_{k-1}+1 \leq i \leq n_{k}$ ) is then given by

$$
\triangle c_{C i}=\frac{\partial R^{\left(n_{k}\right)}\left(\mathbf{q}^{*}\right)}{\partial q_{i}}-\frac{\partial \widetilde{R}\left(\mathbf{q}^{*}\right)}{\partial q_{i}}=M R_{i}^{\left(n_{k}\right)}\left(\mathbf{q}^{*}\right)-\widetilde{M R_{i}}\left(\mathbf{q}^{*}\right)
$$


which returns first-order conditions

$$
Q_{i}(\mathbf{p})+\sum_{j=n_{k-1}+1}^{n_{k}}\left(p_{j}-c_{j}\left(\mathbf{q}_{k}\right)\right) \frac{\partial Q_{j}(\mathbf{p})}{\partial p_{i}}=0, \text { for } i=n_{k-1}+1, \ldots, n_{k} .
$$

These first-order conditions typically depend on the marginal cost of production of all the merging firm's products. Therefore, in Bertrand competition, matters are slightly more complicated than in Cournot competition. The reason for this asymmetry is that increasing production of one commodity in a Cournot model will also influence the prices of the other commodities, but it will not influence production of the other commodities and hence will leave (marginal) costs unchanged. On the other hand, increasing the price for a commodity will influence the demand of other commodities and thereby change production and marginal costs for these other commodities, so that these do enter the first-order conditions. ${ }^{17}$ The endogenous marginal cost levels that assure any particular Bertrand-Nash equilibrium are therefore less obvious to extract.

In matrix notation, the pre-merger first-order conditions of the $l$ merging firms can be compactly expressed as

$$
\mathbf{q}^{\left(n_{l}\right)}+\mathbf{Q}_{0}\left(\mathbf{p}^{\left(n_{l}\right)}-\mathbf{c}^{\left(n_{l}\right)}\right)=\mathbf{0} .
$$

Here

$$
\mathrm{Q}_{0}=\left(\begin{array}{cccc}
\mathrm{Q}_{11} & \mathbf{0} & \cdots & \mathbf{0} \\
\mathbf{0} & \mathrm{Q}_{22} & & \vdots \\
\vdots & & \ddots & \\
\mathbf{0} & \cdots & & \mathrm{Q}_{l l}
\end{array}\right)
$$

is assumed to be an invertible $n_{l} \times n_{l}$ matrix with submatrices

$$
\mathbf{Q}_{i j}=\left(\begin{array}{cccc}
\frac{\partial Q_{n_{i-1}+1}(\mathbf{p})}{\partial p_{n_{j-1}+1}} & \frac{\partial Q_{n_{i-1}+2}(\mathbf{p})}{\partial p_{n_{j-1}+1}} & \cdots & \frac{\partial Q_{n_{i}}(\mathbf{p})}{\partial p_{n_{j-1}+1}} \\
\frac{\partial Q_{n_{i-1}+1}(\mathbf{p})}{\partial p_{n_{j-1}+2}} & \frac{\partial Q_{n_{i-1}+2}(\mathbf{p})}{\partial p_{n_{j-1}+2}} & \cdots & \frac{\partial Q_{n_{i}}(\mathbf{p})}{\partial p_{n_{j-1}+2}} \\
\vdots & \vdots & \ddots & \vdots \\
\frac{\partial Q_{n_{i-1}+1}(\mathbf{p})}{\partial p_{n_{j}}} & \frac{\partial Q_{n_{i-1}+2}(\mathbf{p})}{\partial p_{n_{j}}} & \cdots & \frac{\partial Q_{n_{i}}(\mathbf{p})}{\partial p_{n_{j}}}
\end{array}\right) .
$$

Similar to the matrix of quantity effects (6), matrix (12) represents the transpose of the Jacobian matrix of demand functions of the products produced by firm $i$, with respect to the prices of the products produced by firm $j$. $\mathbf{Q}_{0}$ thus collects all pre-merger price-effects of all the commodities involved in the notified merger.

The post-merger first-order conditions for the fully merged entity are

$$
Q_{i}(\mathbf{p})+\sum_{j=1}^{n_{l}}\left(p_{j}-\widetilde{c}_{j}\left(\mathbf{q}^{\left(n_{l}\right)}\right)\right) \frac{\partial Q_{j}(\mathbf{p})}{\partial p_{i}}=0 \text { for } i=1, \ldots, n_{l},
$$

\footnotetext{
${ }^{17}$ Compare equations (5) and (10).
} 
which can be written as

$$
\mathbf{q}^{\left(n_{l}\right)}+\mathbf{Q}_{1}\left(\mathbf{p}^{\left(n_{l}\right)}-\widetilde{\mathbf{c}}^{\left(n_{l}\right)}\right)=\mathbf{0},
$$

where

$$
\mathbf{Q}_{1}=\left(\begin{array}{cccc}
\mathrm{Q}_{11} & \mathrm{Q}_{21} & \cdots & \mathrm{Q}_{l 1} \\
\mathrm{Q}_{12} & \mathrm{Q}_{22} & & \vdots \\
\vdots & & \ddots & \\
\mathrm{Q}_{1 l} & \cdots & & \mathrm{Q}_{l l}
\end{array}\right)
$$

is assumed to be invertible.

Combining equation (11) and (13), the vector of CMCRs follows as - with subscript 'B' referring to Bertrand competition:

$$
\triangle \mathbf{c}_{B}=\mathbf{c}^{\left(n_{l}\right)}-\widetilde{\mathbf{c}}^{\left(n_{l}\right)}=\left(\mathbf{Q}_{0}^{-1}-\mathbf{Q}_{1}^{-1}\right) \mathbf{q}^{\left(n_{l}\right)} .
$$

Note that under the invertibility assumptions, the elements of $\triangle \mathbf{c}_{B}$ are uniquely determined. ${ }^{18}$

As a result of discontinuities in demand, the case of Bertrand competition in a single homogenous commodity is not a straightforward special case of the analysis above. Assume that the marginal costs of production are constant. If the firms involved are not equally efficient, the most efficient firm would serve all of the market pre-merger. Naturally, therefore, all production remains in that division post-merger. Yet, prices are constrained by the production costs of each commodity's nearest (potential) contestant in terms of efficiency. As a result, it is only mergers involving the two most efficient firms that should raise antitrust concerns in homogenous goods Bertrand competition. The CMCR of the pre-merger most efficient firm then needs to be such that the profit maximizing prices of the merged firm are equal to the premerger marginal costs of the second most cost-efficient producer in the pre-merger equilibrium $\left(c_{2}\right)$. That is, for this special case

$$
\widetilde{c}_{B}=c_{2}+\frac{Q_{i}\left(c_{2}\right)}{Q_{i}^{\prime}\left(c_{2}\right)} \text { and } \Delta c_{B}=c_{B}-\widetilde{c}_{B} .
$$

Note that it is still natural here to use pre-merger production levels as a benchmark for the post-merger situation.

\subsection{CMCRs in Partial Acquisitions}

In both the US and Europe, competition authorities may challenge acquisitions of part of one or more firms. Partial acquisitions may raise competition concerns if the integration of mutual interests implies control over a former rival. The relationship between ownership and control is complex in general, but particularly so in the case

\footnotetext{
${ }^{18}$ The results obtained in Werden (1996) follow straightforwardly as a special case with $l=2$ and constant marginal costs.
} 
of partial and asymmetric equity ownership acquisitions. However, even when partial equity ownership does not convey operating control, the linking of profits can provide anticompetitive unilateral incentives ranging from softened competition to full joint profit maximization. ${ }^{19}$ Furthermore, mergers by sequential partial acquisitions may be a long-term concentration strategy. ${ }^{20}$ For these reasons, merger regulations recognize the possibility of sole control, even in the case of qualified minority share holdings. Similarly, and particularly in the case of joint-ventures, there are potential efficiencies in partial equity interests. In this subsection, we therefore determine CMCRs for more general ownership structures.

Consider the following $n_{l} \times n_{l}$ ownership matrix

$$
\left(\begin{array}{cccc}
w_{11} & w_{12} & \cdots & w_{1 n_{l}} \\
w_{21} & w_{22} & & \\
\vdots & & \ddots & \\
w_{n_{l} 1} & & & w_{n_{l} n_{l}}
\end{array}\right)
$$

where $0 \leq w_{i j} \leq 1$ is the equity share that firm $i$ has in firm $j$. Assuming all profits are indeed paid out to the owners, $\sum_{i=1}^{n} w_{i j}=1$ for all $j$. Given the distribution of ownership, firm $j$ maximizes its profits $\sum_{j=1}^{n_{l}} w_{i j} \pi_{j}$, either by setting its production level $q_{j}$ (in case of Cournot competition) or its price $p_{j}$ (in case of Bertrand competition), while taking into account the effect that the values of its own choice variables have on the profits of the firms it owns equity in.

For analytical convenience, and following Froeb and Tschantz (2001), we rescale the ownership weights in such a way that $w_{i i}=1$ for each $i$. Note that this can in principle be done without affecting the optimization problem for individual firmsalthough this may involve a slight rearranging of labels. Let this modified ownership matrix be $\mathbf{W}$. If each firm produces exactly one product and obtains all profits from that production, $\mathbf{W}$ equals the identity matrix. If a firm produces several commodities, this is represented by a square submatrix consisting of ones. For example,

$$
\mathbf{W}=\left(\begin{array}{lll}
1 & 1 & 0 \\
1 & 1 & 0 \\
0 & 0 & 1
\end{array}\right)
$$

corresponds to a situation where there are two firms, of which the first produces the first two commodities and the second the third commodity. A full merger between these two firms would be presented by a new matrix consisting only of ones. Partial mergers correspond in this framework to off-diagonal elements $w_{i j}$ taking on values different from 0 or 1 . Note that the ownership matrix is typically not symmetric.

This setup allows for a straightforward expression of CMCRs when the ownership structure changes from $\mathbf{W}_{0}$ to $\mathbf{W}_{1}$. Consider a market in Cournot competition.

\footnotetext{
${ }^{19}$ See Reynolds and Snapp (1986) and Reitman (1994).

${ }^{20}$ See Kamien and Zang (1993).
} 
Quantity $q_{i}$ is set in order to solve

$$
\max _{q_{i}} \sum_{j=1}^{n_{l}} w_{i j}\left(q_{j} P_{j}(\mathbf{q})-C_{j}\left(q_{j}\right)\right) .
$$

Note that we have specialized the cost structure to $C(\mathbf{q})=\sum_{j=1}^{n_{j}} C_{j}\left(q_{j}\right)$. That is, we abstract in the following from cross-cost efficiencies, which would typically be very complex to trace in partial mergers.

First-order conditions with respect to commodity $i$ are given by

$$
P_{i}(\mathbf{q})-c_{i}\left(q_{i}\right)+\sum_{j=1}^{n_{l}} w_{i j} \frac{\partial P_{j}}{\partial q_{i}} q_{j}=0, \text { for } i=1, \ldots, n_{l},
$$

which in matrix notation can be written as

$$
\mathbf{p}^{\left(n_{l}\right)}+\mathbf{W}_{0} \bullet \mathbf{P} \mathbf{q}^{\left(n_{l}\right)}-\mathbf{c}^{\left(n_{l}\right)}=\mathbf{0}
$$

where • corresponds to the Hadamard product. $^{21}$ Post-partial acquisition, that is, with the ownership structure changed from $\mathbf{W}_{0}$ to $\mathbf{W}_{1}$, the status quo $(\mathbf{p}, \mathbf{q})$ is obtained if

$$
\mathbf{p}^{\left(n_{l}\right)}+\mathbf{W}_{1} \bullet \mathbf{P q}-\widetilde{\mathbf{c}}^{\left(\mathbf{n}_{\mathbf{l}}\right)}=\mathbf{0} .
$$

Therefore, the unique absolute CMCRs read

$$
\triangle \mathbf{c}_{C}=\left(\mathbf{p}^{\left(n_{l}\right)}-\widetilde{\mathbf{c}}^{\left(n_{l}\right)}\right)-\left(\mathbf{p}^{\left(n_{l}\right)}-\mathbf{c}^{\left(n_{l}\right)}\right)=\left(\mathbf{W}_{0}-\mathbf{W}_{1}\right) \bullet \mathbf{P} \mathbf{q}^{\left(n_{l}\right)} .
$$

If firms compete in prices, the analogous problem is firm $i$ maximizing profits with respect to $p_{i}$. That is,

$$
\max _{p_{i}} \sum_{j=1}^{n_{l}} w_{i j}\left(p_{j} Q_{j}(\mathbf{p})-C_{j}\left(Q_{j}(\mathbf{p})\right)\right),
$$

which returns first-order conditions

$$
Q_{i}(\mathbf{p})+\sum_{j=1}^{n_{l}} w_{i j}\left(p_{j}-c_{j}\left(q_{j}\right)\right) \frac{\partial Q_{j}}{\partial p_{i}}=0
$$

or

$$
\mathbf{q}^{\left(n_{l}\right)}+\mathbf{W}_{0} \bullet \mathbf{Q}\left(\mathbf{p}^{\left(n_{l}\right)}-\mathbf{c}^{\left(n_{l}\right)}\right)=\mathbf{0} .
$$

Comparing these to the corresponding first-order conditions after the change in ownership structure at status quo quantities and prices,

$$
\mathbf{q}^{\left(n_{l}\right)}+\mathbf{W}_{1} \bullet \mathbf{Q}\left(\mathbf{p}^{\left(n_{l}\right)}-\mathbf{c}^{\left(n_{l}\right)}\right)=\mathbf{0},
$$

the unique absolute CMCRs are found to be

$$
\triangle \mathbf{c}_{B}=\left(\mathbf{p}^{\left(n_{l}\right)}-\widetilde{\mathbf{c}}^{\left(n_{l}\right)}\right)-\left(\mathbf{p}^{\left(n_{l}\right)}-\mathbf{c}^{\left(n_{l}\right)}\right)=\left(\left(\mathbf{W}_{0} \bullet \mathbf{Q}\right)^{-1}-\left(\mathbf{W}_{1} \bullet \mathbf{Q}\right)^{-1}\right) \mathbf{q}^{\left(n_{l}\right)} .
$$

\footnotetext{
${ }^{21}$ The Hadamard, or entry-wise, product $\mathbf{A} \bullet \mathbf{B}$ of two $m_{1} \times m_{2}$ matrices $\mathbf{A}$ and $\mathbf{B}$ gives an $m_{1} \times m_{2}$ matrix for which the $(i, j)$-element is given by $a_{i j} b_{i j}$.
} 


\section{The Werden-Froeb-Index}

The generalized CMCRs characterized above are commodity-specific and may vary considerably over the products involved in the merger. For practical use of the concept in merger control, the Werden-Froeb-Index collects the different CMCRs into an average required (marginal) cost savings. The WFI is defined generally as

$$
W F I=\frac{\sum_{i=1}^{n_{l}} q_{i} \triangle c_{i}}{\sum_{i=1}^{n_{l}} q_{i} c_{i}}=\frac{\triangle \mathbf{c} \cdot \mathbf{q}^{\left(n_{l}\right)}}{\mathbf{c} \cdot \mathbf{q}^{\left(n_{l}\right)}},
$$

that is, as the sum of CMCRs, each weighted by the quantity produced, divided by the sum of the product of marginal costs and quantity. ${ }^{22}$

The WFI can be thought of as the average percentage of cost savings required to replicate the pre-merger market outcome. It weighs those required efficiencies that need to materialize on the products that have a larger share in total production more than on less important products. The WFI summarizes the generalized CMCRs in a single statistic, providing a measure of the total relative decrease in the total marginal costs of producing the commodities involved in the merger required to preserve the status quo. It gives an idea of how much more cost efficient the merged firm must produce after the merger for its merger-specific efficiency gains to overcome the merger's anticompetitive effects.

Using the generalized CMCRs derived above for the case of Cournot and Bertrand competition, the WFI specializes to the following two measures. When firms compete in quantities:

$$
W F I_{C}=\frac{\left(\mathbf{P}_{0}-\mathbf{P}_{1}\right) \mathbf{q}^{\left(n_{l}\right)} \cdot \mathbf{q}^{\left(n_{l}\right)}}{\mathbf{c} \cdot \mathbf{q}^{\left(n_{l}\right)}}=\frac{\left(\mathbf{q}^{\left(n_{l}\right)}\right)^{T}\left(\mathbf{P}_{0}-\mathbf{P}_{1}\right)^{T} \mathbf{q}^{\left(n_{l}\right)}}{\mathbf{c} \cdot \mathbf{q}^{\left(n_{l}\right)}}
$$

with, using equations (17), $\mathbf{P}_{0}=\mathbf{W}_{0} \bullet \mathbf{P}$ and $\mathbf{P}_{1}=\mathbf{W}_{1} \bullet \mathbf{P}$, in case of partial acquisitions. $^{23}$

\footnotetext{
${ }^{22}$ Alternatively, the CMCRs can be weighted by the merger-involved commodities' share in revenue. The behavior of the thus defined index is very similar to the WFI, but is both less natural and not so convenient to apply.

${ }^{23}$ Note that in the case of a single homogenous commodity market
}

$$
W F I_{C}=\frac{\sum_{i=1}^{l} \triangle c_{i} q_{i}}{\sum_{i=1}^{l} c_{i} q_{i}}=-\frac{2 P^{\prime}(\mathbf{q}) \sum_{i=1}^{l} \sum_{j=i+1}^{l} q_{i} q_{j}}{P(\mathbf{q}) \sum_{i=1}^{l} q_{i}+P^{\prime}(\mathbf{q}) \sum_{i=1}^{l} q_{i}^{2}} .
$$

which, with $\epsilon=-\frac{p}{Q} \frac{\partial Q}{\partial p}$ and $s_{i}=\frac{q_{i}}{Q}$, reduces to

$$
W F I_{C}=\frac{2 \sum_{i=1}^{l} \sum_{j=i+1}^{l} s_{i} s_{j}}{\epsilon \sum_{i=1}^{l} s_{i}-\sum_{i=1}^{l} s_{i}^{2}}=\frac{2 s_{j} s_{k}}{\boldsymbol{\epsilon}\left(s_{j}+s_{k}\right)-\left(s_{j}^{2}+s_{k}^{2}\right)},
$$

for two merging products $j$ and $k$. This is exactly "the proportionate reduction in marginal cost necessary to restore the pre-merger price", or equation (4), in Froeb and Werden (1998), p.368. 
When competition is on prices:

$$
W F I_{B}=\frac{\left(\mathbf{Q}_{0}^{-1}-\mathbf{Q}_{1}^{-1}\right) \mathbf{q}^{\left(n_{l}\right)} \cdot \mathbf{q}^{\left(n_{l}\right)}}{\mathbf{c} \cdot \mathbf{q}^{\left(n_{l}\right)}}=\frac{\left(\mathbf{q}^{\left(n_{l}\right)}\right)^{T}\left(\mathbf{Q}_{0}^{-1}-\mathbf{Q}_{1}^{-1}\right)^{T} \mathbf{q}^{\left(n_{l}\right)}}{\mathbf{c} \cdot \mathbf{q}^{\left(n_{l}\right)}},
$$

in which to replace, using equations (19), $\mathbf{Q}_{0}=\mathbf{W}_{0} \bullet \mathbf{Q}$ and $\mathbf{Q}_{1}=\mathbf{W}_{1} \bullet \mathbf{Q}$ in case of partial acquisitions.

Since the CMCR values are unique, and pre-merger sales volumes are given, note that the value of the WFI for each type of competition is unique. Furthermore, the index satisfies several natural axioms regarding proportionality and commensurability. If all relative CMCRs, $\frac{\Delta c_{i}}{c_{i}}$, are identical, then the WFI is equal to this relative required reduction. If the unit of measurement of marginal costs changes, the value of the WFI is unaffected. ${ }^{24}$ The WFI is determinate in marginal costs and quantities - although the likelihood of the required post-merger cost levels falling below zero increases when pre-merger marginal cost levels are close to zero. Finally, the measure deals quite naturally with required efficiencies that are so large that post-merger production costs would need to fall below zero, since in the event that $\Delta c_{i}>c_{i}$, the value of the WFI is high.

\section{Information Requirements}

Since, by construction, post- and pre-merger quantities and prices are identical, calculating the WFI for the purpose of merger control requires a relatively low amount of information that is directly observable. Since the CMCRs are a local measure, the WFI is independent of the specific functional forms of market demand and cost of production. It only uses information on the commodities that are involved in the proposed merger. More specifically, apart from existing and proposed ownership matrices, it suffices to know the quantities sold of the products offered by the merging firms prior to the merger $\left(\mathbf{q}^{(l)}\right)$, the sales prices $\left(\mathbf{p}^{\left(n_{l}\right)}\right)$, the nature of competition (Cournot or Bertrand), and depending on the latter, the matrix of the affected commodities' quantity-effects ( $\mathbf{P}_{1}$ in the case of Cournot competition) or price-effects $\left(\mathbf{Q}_{1}\right.$ in the case of Bertrand competition), both evaluated at the pre-merger market equilibrium. Matrices $\mathbf{P}_{0}$ and $\mathbf{Q}_{0}$ follow directly from $\mathbf{P}_{1}$ and $\mathbf{Q}_{1}$ by setting all appropriate elements equal to zero.

It is common practice in merger control to obtain and evaluate demand elasticity matrices, rather than just the derivatives and cross-derivatives of (inverse) demand. Regular demand elasticity matrices premultiply price over quantity by the partial derivative of demand with respect to price. The information on $\mathbf{Q}_{1}$ necessary to establish CMCRs in a market in Bertrand competition can therefore be recovered

\footnotetext{
${ }^{24}$ Note that a change in all quantities by the same factor does in general affect the value of the WFI, since it implies a discrete shift in production. The requirement of proportionality in quantities, however, is not in line with the status quo nature of the analysis.
} 
from standard demand elasticity information, using information on $\mathbf{q}^{(l)}$ and $\mathbf{p}^{\left(n_{l}\right)} .^{25}$ It is not equally straightforward to determine $\mathbf{P}_{1}$ on the basis of regular demand elasticities. That would require separate specific information on the 'inverse demand elasticities', which is not a common concept.

Alternatively, information may be available on either the full $n \times n$ Jacobian matrix of price-effects or the full $n \times n$ Jacobian matrix of quantity-effects. In that case, the one follows directly as the inverse of the other. Obviously, to know the price- or quantity effects of all commodities in the relevant market is a considerably stronger information requirement than the information on only the affected commodities. Yet, it may be that certain proportionality assumptions apply market wide that allow to construct the full Jacobian from limited information. In Epstein and Rubinfeld (2001), for example, on the assumption that substitution between products is according to their relative market shares, a full approximate demand-elasticity matrix is constructed on the basis of information only about the industry elasticity of demand plus one own-price elasticity. Variations to this specific proportionality assumption obviously return different matrices.

The denominator of the index uses the marginal cost of production. It is not necessary to separately obtain this information, however, as the marginal costs of production are implied by the first-order conditions (8) for Cournot competition and (13) for Bertrand competition. The different marginal production cost levels can straightforwardly be recovered, given sales prices and traded volumes. ${ }^{26}$ Total actual (variable) costs of production could be used as a proxy for the base. Although this would stay true to the conceptual nature of the WFI, the use of accounting data is unreliable. Firms may furthermore attempt to manipulate the WFI values of their merger downwards by overstating pre-merger production costs. Finally note that, if need be, the CMCRs and WFI can straightforwardly be formulated in terms of diversion ratios, a concept used in Shapiro (1996) in Werden (1996).

${ }^{25}$ That is, given the $n \times n$ elasticity-matrix

$$
\boldsymbol{\Omega}=\left(\begin{array}{cccc}
\varepsilon_{11} & \varepsilon_{12} & \cdots & \varepsilon_{1 n} \\
\varepsilon_{21} & \varepsilon_{22} & & \\
\vdots & & \ddots & \\
\varepsilon_{n 1} & & & \varepsilon_{n n}
\end{array}\right)
$$

where

$$
\varepsilon_{i j}=\frac{\partial q_{i}}{\partial p_{j}} \frac{p_{j}}{q_{i}}
$$

and given prices $\mathbf{p}=\left(p_{1}, \ldots, p_{n}\right)$ and quantities $\mathbf{q}=\left(q_{1}, \ldots, q_{n}\right)$, the matrix of price-effects $\mathbf{Q}$ can be recovered as

$$
\mathbf{Q}^{T}=D(\mathbf{q}) \boldsymbol{\Omega}[D(\mathbf{p})]^{-1},
$$

where $D(\mathbf{q})$ and $D(\mathbf{p})$ are diagonal matrices, in which the $(i, i)$ th element is $q_{i}$ or $p_{i}$, respectively.

${ }^{26}$ This is identical to using the Lerner-index for this purpose. See Dansby and Willig (1979), or the discussion in Neven et al. (1994). 


\section{The WFI in Merger Control}

In their assessment of horizontal mergers, competition authorities attach considerable value to the Hirschman-Herfindahl-index (HHI) as a measure of market concentration. Merger regulations and guidelines specify threshold values of the HHI for the purpose of self-assessment. Given that the combination of the absolute value of the HHI and the change in its value, $\Delta \mathrm{HHI}$, remains below specified critical values, competition authorities in both the US and Europe are unlikely to find horizontal competition concerns, as stated in their respective merger guidelines. ${ }^{27}$ Only if either of these measures, or both, surpass these values is a deeper Phase II investigation entered.

The use of the HHI for the purpose of assessing whether a merger can be expected to lead to a "substantial lessening" or "significant impediment" of effective competition is not without problems, however. The measure can be deceptively straightforward and miss the competitive discipline of potential entrants, for example in bidding markets. But also in markets where it does apply, the HHI does not discriminate between detrimental and socially desirable mergers. Furthermore, the proper determination of the relevant market is complex and controversial. Also, the HHI uses pre-merger markets shares, thus ignoring the post-merger market effects that it is intended to advise on. Firms may, in reply, attempt to tailor their merger plans so as to stay just within the HHI safe-haven. Most importantly, the analysis is of no assistance in assessing merger-specific efficiency gains. Instead, these only come into consideration in a full Phase II inquiry, which is costly and may have unpredictable outcomes. As a result, it is difficult for firms to self-assess their possibilities for a successful efficiency defense.

The WFI can supplement merger control by providing guidance in this. This would extend the de minimus doctrine to include efficiency claims. As a matter of standard procedure, in notifying a horizontal merger firms would be required to submit the value of the WFI for their proposed merger - along with documented calculations. ${ }^{28}$ This value complements the more general argumentation that efficiency gains can indeed be expected to materialize as a result of the merger. The burden of proof therefore remains on the parties proposing the merger. The validity of the submitted analysis is to be assessed by the competition authorities and can be challenged, in which case the merger can be blocked. The merger guidelines would specify threshold values of the WFI which, in combination with critical HHI values, would in principle allow the merger, even when it does raise competition concerns. That is, a sufficiently low (and credible) WFI value can compensate an $H H I$ or $\Delta H H I$ value

\footnotetext{
${ }^{27}$ In the US, this is so for all mergers for which the HHI remains below 1000 and all for which $\Delta$ HHI remain below 50, as well as for any combination of HHI, $\Delta$ HHI below 1800 and 100 - see Section 1.5 of US Department of Justice and US Federal Trade Commission (1997). In the EU, these critical values are $\mathrm{HHI}=1000, \Delta \mathrm{HHI}=150$, and those combinations below 2000 and 250 - see paragraphs 19 and 20 of Commission of the European Communities (2004).

${ }^{28}$ Appendix $A$ provides an algorithm in MATLAB ${ }^{\circledR}$ for this purpose. See http://wfi.acle.nl for a user-friendly on-line version.
} 
over and above the safe-haven thresholds. A Phase II investigation will only be initiated if unreasonably high compensating cost reductions are necessary to overcome the anti-competitive effects of the merger. Alternatively, a second and upper-bound critical (delta) HHI value may be specified, such that a Phase II investigation is always entered when the merger surpasses this upper-bound threshold, irrespective of its WFI.

To illustrate the proposed application of the WFI and its power in supplementing HHI analysis, consider a hypothetical representative pre-merger market in which eight firms are in Bertrand competition, each producing a single commodity. Table 1 specifies regular prices, quantities and demand elasticities of each of these commodities. $^{29}$

\begin{tabular}{c||c|c|cccccccc} 
\# & Price & Volume & $\mathbf{1}$ & $\mathbf{2}$ & $\mathbf{3}$ & $\mathbf{4}$ & $\mathbf{5}$ & $\mathbf{6}$ & $\mathbf{7}$ & $\mathbf{8}$ \\
\hline \hline $\mathbf{1}$ & 400 & 36.0 & -1.500 & 0.010 & 0.200 & 0.045 & 0.125 & 0.425 & 0.001 & 0.020 \\
$\mathbf{2}$ & 450 & 15.0 & 0.001 & -1.500 & 0.211 & 0.061 & 0.110 & 0.425 & 0.005 & 0.015 \\
$\mathbf{3}$ & 483 & 25.7 & 0.377 & 0.095 & -1.500 & 0.045 & 0.201 & 0.415 & 0.001 & 0.013 \\
$\mathbf{4}$ & 375 & 33.1 & 0.085 & 0.029 & 0.050 & -2.400 & 0.910 & 0.515 & 0.006 & 0.035 \\
$\mathbf{5}$ & 365 & 93.6 & 0.085 & 0.035 & 0.065 & 0.175 & -2.450 & 0.100 & 0.150 & 0.100 \\
$\mathbf{6}$ & 400 & 161.8 & 0.045 & 0.015 & 0.036 & 0.065 & 0.100 & -1.400 & 0.300 & 0.035 \\
$\mathbf{7}$ & 410 & 100.6 & 0.050 & 0.020 & 0.020 & 0.315 & 0.100 & 0.200 & -2.900 & 0.100 \\
$\mathbf{8}$ & 390 & 10.0 & 0.010 & 0.010 & 0.100 & 0.300 & 0.200 & 0.100 & 0.300 & -3.300
\end{tabular}

Table 1: Prices, sales volumes (in thousands) and elasticities in representative market.

Between the eight firms, there are twenty-eight different complete two-party mergers possible. For all these potential combinations, Figure 1 plots the $W F I_{B}$ versus $\Delta$ HHI. $^{30}$ Two vertical lines mark the lowest threshold values of $\Delta H H I=50$ for US merger regulation, and $\Delta \mathrm{HHI}=150$ for EU merger control. As explained above, below these values, mergers are in principle not challenged, independent of their absolute HHI value. A potential threshold value for the $W F I_{B}$ is drawn in at $10 \%$.

The figure reiterates the weak relationship between CMCRs and HHI or $\triangle \mathrm{HHI}$ pointed out by Werden and Froeb in their papers. The mergers that are grouped in the lower-left corner of the figure remain below the EU and/or US threshold values for $\triangle \mathrm{HHI}$ and require only relatively low efficiency gains as measured by the $W F I_{B}$. Allowing these mergers to be consummated on standard HHI assessment is in principle correct. Yet, a number of mergers involve high levels of either $\Delta \mathrm{HHI}$ or

\footnotetext{
${ }^{29}$ The elasticity matrix is so defined that, for example, entry $(1,2)$ represents the elasticity of the demand for commodity 1 with respect to changes in the price of commodity 2 , that is, $\epsilon_{12}=\frac{\partial q_{1}}{\partial p_{2}} \frac{p_{2}}{q_{1}}=$ 0.01 .

${ }^{30}$ Although this example was constructed, it was inspired by an actual merger. Moreover, it is generic, in that the qualitative effects are robust to (substantial) changes in all the underlying data. The reader is invited to work with the example, or any other set of merger data, using the MATLAB ${ }^{\circledR}$ routine in Appendix $A$. Note that the dot in the origin of Figure 1 represents eight overlaying cases of firms merging with themselves.
} 


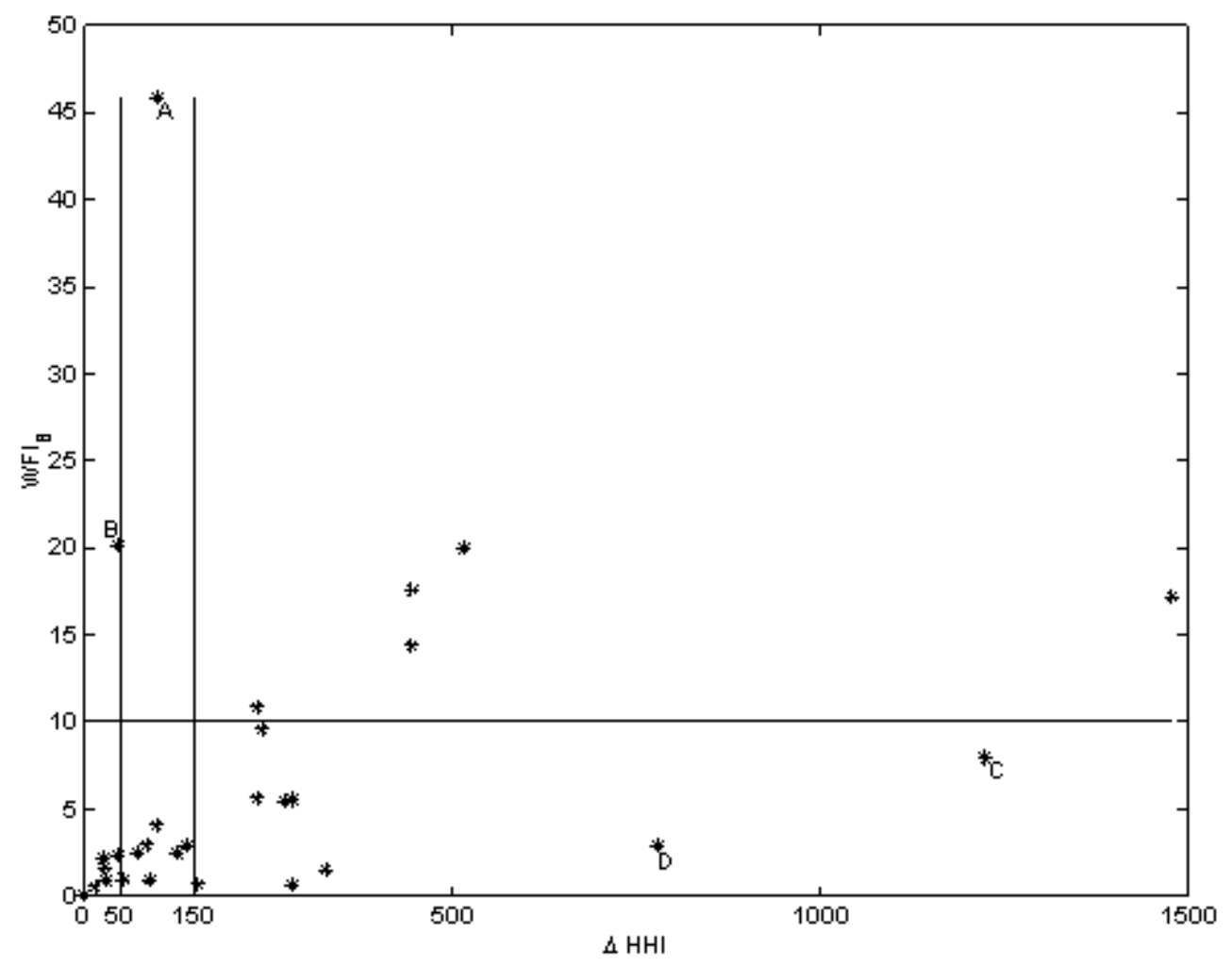

Figure 1: $W F I_{B}$ versus $\triangle \mathrm{HHI}$ for representative mergers.

$W F I_{B}$. Consider the merger labelled $A$ in Figure 1, which is between firms 1 and 3 , which are both relatively small with respective market shares of $7.6 \%$ and $6.5 \%$. The HHI increases through this merger from 2114 to 2213 , that is, $\Delta H H I=99$. The merger's $W F I_{B}$ value is $45.8 \%$. By relying on HHI-analysis alone, without quantifying efficiency gains, this merger would in principle pass European (albeit not US) merger control without remedies, even though it requires considerable merger specific efficiency gains to overcome the anticompetitive effects of the merger.

Merger $B$, as another example, has a $\Delta \mathrm{HHI}=47$ and would therefore probably not be challenged in either jurisdiction. It is a merger of firm 2 with firm 3. Firm 2 has a market share of $3.6 \%$, which is smaller than that of firm 1 . In addition, the cross-price elasticity of firm 3's commodity with respect to the price of commodity 1 is roughly fourfold that of commodity 3 with respect to the price of commodity 2. As a result, the $W F I_{B}$ is substantially lower, yet still as high as $20.1 \%$, which may be too much to expect to materialize as a result of the merger. Relying only on standard HHI analysis, without a proper assessment of merger specific efficiencies, therefore poses a risk of Type II error, that is, of allowing a merger that should have been blocked from the point of view of consumer welfare. 
An example of a merger with the opposite danger is merger $C$, which is between firms 5 (market share: 18\%) and 6 (market share: $34.1 \%$ ). Here, the HHI increases to 3339 , that is $\Delta \mathrm{HHI}=1225$, as a result of the substantial market shares of the two firms involved in the merger. Yet, the $W F I_{B}=7.9 \%$. Even though the merger would certainly be challenged, trigger an in-depth investigation, and quite possibly be blocked under both European and US merger regulations, the efficiencies minimally needed for this merger to be welfare enhancing are relatively low. Therefore, Phase II investigation costs could be saved if our proposal to include WFI analysis in merger regulation would be adopted. Indeed, supplementing merger control with $W F I$ analysis has the largest potential for saving on enforcement costs in this category. Mergers that stay below a set WFI threshold value and an additional $\Delta \mathrm{HHI}$ threshold need then not enter into a Phase II investigation, whereas they would under the present merger criteria. ${ }^{31}$

The described use of the WFI has a number of benefits. The WFI is an exact and well-defined measure, that requires information that is standard available in the market. The measure is easy to interpret and standardizes the submission of evidence for an efficiency defense in Phase I inquiries. The WFI is independent of the functional form of demand and costs, and not sensitive to other model specifics as costly merger simulation analyses often are. Therefore, there is little room for presenting overly rosy efficiency claims. At best, the merging parties can downwardly manipulate the WFI by overstating their post-merger own-elasticities and under-stating their crosselasticities. This respectively gives the impression of more than actual competition for their products generally, and less than actual competition between the mergerinvolved commodities. This reduces the anti-competitive effects of the merger, so that its WFI value will be lower. The space for such manipulations is limited, however. Also, wider definitions of the relevant market that reduce market shares have only little effect on the WFI.

As the minimally required efficiencies are compared to a fixed target that is specified in the guidelines, use of the WFI leaves little scope for rent seeking by the notifying firms. As a result, the measure avoids complex and expensive litigation and administrative procedures. As a single statistic, the index can be published without publicly revealing the underlying data, which is often confidential. In addition, in the case of divestitures or partial mergers, threshold WFI values can guide allowable mutual equity acquisitions. Furthermore, the WFI is inherently based on the consumer welfare standard - which is the principle guidance for both US and EU competition authorities. As a measure of minimally required efficiencies, any merger-specific gains that would materialize over and above it would directly benefit consumers in the postmerger equilibrium.

The WFI furthermore is an upper-bound requirement. In line with the consumer

\footnotetext{
${ }^{31}$ This second $\triangle H H I$ threshold value would have to be established on the basis of systematic research. Note also that, at a threshold WFI-value of 5\%, there remains a Type II error candidate: merger $D$ between firms $5(18 \%)$ and $7(21,7 \%)$, which returns a $\Delta H H I=781$, yet the $W F I_{B}=2.9 \%$.
} 
welfare standard, it disallows fixed costs synergies that would potentially contribute to total welfare. It further does not take into account more sophisticated long-term benefits that may result from the merger, such as product innovations from combined R\&D efforts, which are very difficult to quantify. Moreover, as noted above, the concept of the CMCRs - and consequently the WFI - expressly ignores any post-merger cost-minimizing redistribution of production to those division(s) in the merged firm with the most efficient production technology. In simple settings with a homogenous good produced at constant marginal costs of production, such post-merger reallocations are relatively straightforward, since all production will be located in the single most efficient firm. However, to determine post-merger production levels at minimally required efficiency gains generally requires considerably more information on the merging firms. In effect, it would involve a fully specified model of the relevant market, including global information of the multi-product production and cost functions, the functional form and specification of all demands, and possible capacity constraints of all firms. This goes counter to the conceptual idea of the CMCRs as a local measure. It would remove the benefit of using the WFI as a practical statistic in merger control. The implication of ignoring post-merger cost minimization is that the WFI structurally overestimates the truly required marginal cost reductions that compensate consumers for the anti-competitive effects of the merger. ${ }^{32}$ If implemented in future merger guidelines bearing this in mind, however, the WFI can facilitate self-assessment and focus enforcement.

Finally, note that in order to determine what would be proper threshold values for the WFI to be included in future horizontal merger guidelines is - with the caveats pointed out above - a policy decision that is no different from the specification of the present HHI safe-havens. These values may consequently differ similarly across enforcement regimes. Perhaps anything below 5 per cent can be accepted as reasonably low, or maybe 10 per cent, as drawn in Figure 1. One possible way to substantiate these thresholds departs from the following observation. In the past two decades of merger control, a number of mergers initially challenged were eventually cleared after a Phase II investigation or by a court inquiry-with or without divestitures. Apparently, despite raising competition concerns, these mergers satisfied an implicit standard of merger-specific benefits. Using these past decisions, the implied value of the WFI can be backed out to provide some guidance in this policy matter. We leave this for further research.

\section{Concluding Remarks}

The stakes in merger control are high and merit a full weighing of all likely consequences of notified mergers and (partial) acquisitions before deciding to block or

\footnotetext{
${ }^{32}$ This is conceptually comparable to the Laspeyres price index overestimating the true-cost-ofliving index. See Fisher and Shell (1998), Chapter 2, for a survey.
} 
clear them. Even more so than a merger's effects on competition, any claimed mergerspecific efficiencies are hard to substantiate and difficult for the authorities to verify. The WFI assists in this assessment. The measure integrates concentration and efficiency effects, and asks what average percentage of total (variable) cost savings need minimally materialize as a result of the merger to compensate consumers for its anticompetitive effects. If the WFI is low, the burden of proof on the proponents of the merger can be lower than when considerable compensating efficiencies are required. Threshold values can be set, below which no extensive investigation is required. The WFI is a point measure that is straightforward to implement, exact, informationally efficient, well-behaved and natural to interpret. It standardizes merger procedures. The measure can provide legal guidance in self-assessment and facilitate the mounting of an efficiency defense, without necessarily opening a full merger inquiry.

Obviously, standardizing the efficiency defense in future horizontal merger guidelines along the lines here proposed does not relieve the competition authorities from their obligation to carefully assess every merger case. In particular, by ignoring efficient reallocations of production, possible increases in product variety, as well as fixed cost savings, the WFI tends to overestimate the minimally required efficiencies. Depending on global variability in the cost-functions and the relative (cross-)elasticities, therefore, the test may be too strict and lead to desirable mergers being nevertheless blocked. Our proposal to apply the WFI firstly as a filter to Phase II investigations partly remedies this problem.

Finally, as with all standardized tests, also the WFI-analysis can be tricked. In particular, notifying firms can attempt to manipulate the matrix with estimates of quantity- or price-effects. As the local derivatives of demand relate to the availability of substitute commodities, and thus indirectly to the number of firms and the differentiation of their products, the determination of the relevant market, through a SSNIP-test or otherwise, remains a crucial aspect of the analysis. In a more sophisticated manner, in anticipation of a merger firms may want to influence sales prices and quantities. The latter is also a possibility under only the HHI standard, however. Moreover, our generic examples of mergers have so far shown the WFI to be robust to such variations. Faced with the reality that competition law enforcement is costly,

the WFI therefore can reliably enhance merger control by facilitating a standardized two-tier efficiency defense.

\section{References}

[1] Bergeijk, P.A.G. van and E. Kloosterhuis, Modelling European Mergers, Edward Elgar, London, 2005;

[2] Berry, S.T. and J. Waldfogel, "Do Mergers Increase Product Variety? Evidence from Radio Broadcasting," Quarterly Journal of Economics, 116, 2001, 969-1007; 
[3] Commission of the European Communities, "Council Regulation No 139/2004 of 20 January 2004 on the control of concentrations between undertakings," Official Journal, L 24, January 29, 2004, 1-22;

[4] Commission of the European Communities, "Commission Notice: Guidelines on the assessment of horizontal mergers under the Council Regulation on the control of concentrations between undertakings," Official Journal, C 31, February 5, 2004, 5-18;

[5] Dansby, E. and R. Willig, "Industry Performance Gradient Indexes," American Economic Review, 69, 1979, 249-260;

[6] Davidson, C. and R. Deneckere, "Incentives to Form Coalitions with Bertrand Competition;" RAND Journal of Economics, 16, 1985, 473-486;

[7] Epstein, R.J. and D. Rubinfeld, "Merger Simulation: A Simplified Approach with New Applications," Antitrust Law Journal, 69, 2001, 883-919;

[8] Fabrizi, S. and S. Lippert, "How Much Efficiency Gains and Price Reductions to Put as Ingredients into an Efficiency Defense?: 'Quanto Bast'," UPV-DFAEII Working Paper 2004-04, November 2005;

[9] Farrell, J. and C. Shapiro, "Horizontal Mergers: An Equilibrium Analysis," American Economic Review, 80, 1990, 107-206;

[10] Farrell, J. and C. Shapiro, "Scale Economies and Synergies in Horizontal Merger Analysis," Antitrust Law Journal, 68, 2001, 685-710;

[11] Fisher, F.M., "Horizontal Mergers: Triage and Treatment," Journal of Economic Perspectives, 1, 1987, 23-40;

[12] Fisher, F.M.and K., Shell, Economic Analysis of Production Price Indexes, Cambridge: Cambridge University Press, Cambridge, 1998;

[13] Froeb, L.M. and G.J. Werden, "A Robust Test for Consumer Welfare Enhancing Mergers Among Sellers of Homogeneous Products," Economics Letters, 58, 1998, 367-369;

[14] Gandhi, A., L.M. Froeb, S. Tschantz and G.J. Werden, "Post-merger Product Repositioning," Vanderbilt Law \& Economics Working Paper 05-19, 2005;

[15] Goppelsroeder, M. and M.P. Schinkel, "On the Use of Economic Modelling in Merger Control," in: Bergeijk and Kloosterhuis (2005), 53-78;

[16] Heidhues, P. and J. Lagerloef, "On the Desirability of an Efficiency Defense in Merger Control," International Journal of Industrial Organization, 23, 2005, 803-827; 
[17] Kamien, M.I. and I. Zang, "Monopolization by Sequential Acquisition," The Journal of Law, Economics \& Organization, 9. 1993. 205-229;

[18] Kolasky, W.J. and A.R. Dick, "The Merger Guidelines and the Integration of Efficiencies into Antitrust Review of Horizontal Mergers," Antitrust Law Journal, 71(1), 2003, 207-251;

[19] Lyons, B. R., "Reform of European Merger Policy," Review of International Economics, 12, 2004, 246-261;

[20] MATLAB $^{\circledR}$, developed by The MathWorks, http://www.mathworks.com;

[21] Neven, D., R. Nuttall and P. Seabright, Merger in Daylight: The Economics and Politics of European Merger Control, CEPR, London, 1994;

[22] Perry, M.K. and R.H. Porter, "Oligopoly and the Incentive for Horizontal Merger," American Economic Review, 75, 1985, 219-227;

[23] Reitman, D., "Partial Ownership Arrangements and the Potential for Collusion," Journal of Industrial Economics, 42, 1994, 313-322;

[24] Reynolds, R.J. and B.R. Snapp, "The Competitive Effects of Partial Equity Interests and Joint Ventures," International Journal of Industrial Organization, 4, 1986, 141-183;

[25] Röller, L.-H., J. Stennek and F. Verboven, "Efficiency Gains from Mergers," Report for EC Contract II/98/003, 26 February 2001;

[26] Shapiro, C., "Mergers with Differentiated Products," Antitrust Magazine, Spring 1996, 23-30;

[27] Stennek J. and F. Verboven, "Quantitative Techniques to Assess Price Effects of European Merger Control from a Consumers's Perspective," Report for the EC contract no B5-1000/02/000519 between the European Commission and Frank Verboven, 21 May 2003;

[28] US Department of Justice and US Federal Trade Commission, Horizontal Merger Guidelines [with Revisions to Section 4 on Efficiencies], April 8, 1997;

[29] Verboven, F., L.-H. Röller and J. Stennek, "The Efficiency Defence in Merger Analysis," Report for the Economic and Financial Affairs Directorate General of the European Commission, 1999;

[30] Werden, G.J., "A Robust Test for Consumer Welfare Enhancing Mergers Among Sellers of Differentiated Products," Journal of Industrial Economics, 44, 1996, 409-413; 
[31] Werden, G. J., "Simulating the Effects of Differentiated Products Mergers: A Practical Alternative to Structural Merger Policy," George Mason Law Review, 5, 1997, 363-368;

[32] Werden, G. J. and L.M. Froeb, "Simulation as an Alternative to Structural Merger Policy in Differentiated Product Industries," in: M.B. Coate and A.N. Kleit (eds.), The Economics of the Antitrust Process, Kluwer, Boston, 1996;

[33] Werden, G.J. and L.M. Froeb, "Unilateral Competitive Effects of Horizontal Mergers," in: P. Buccirossi (ed.), Advances in Economics of Competition Law, MIT Press, Cambridge, MA, 2006;

[34] White, L.J., "Antitrust and Merger Policy: A Review and Critique," Journal of Economic Perspectives, 1, 1987, 13-22;

[35] Williamson, O.E., "Economies as an Antitrust Defense: The Welfare Tradeoffs," American Economic Review, 58, 1968, 18-36. 


\section{A A MATLAB ${ }^{\circledR}$ Routine for Calculating WFIs}

To illustrate the ease of use of the WFI in merger control, consider the following simple routine, written in MATLAB ${ }^{\circledR}$ for mergers typically encountered by competition authorities. ${ }^{33}$ It calculates the WFI for a full merger between any number of firms, which may pre-merger produce several commodities, in a market that competes in prices.

The required inputs for the software are the matrix of elasticities of commodities involved in the merger $(E m)$, the column vector of status quo prices $(p v)$, and the column vector of status quo quantities ( $q v$ ), as measured on the market. The user can then specify the row vector prior, which has the same dimension as $p v$ and $q v$. For this vector, enter 0 for all products that remain outside of the merger, and a positive number for all products that are involved in the merger, such that: (i) products produced by the same firm pre-merger get the same number; and (ii) products produced by different firms pre-merger get different numbers. For example,

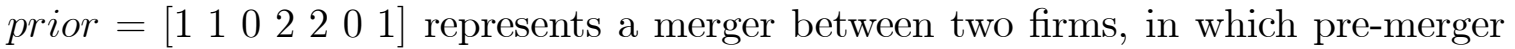
products 1, 2 and 7 are produced by one of the merging firms, products 4 and 5 by the other merging firm, and products 3 and 6 by non-merging firms.

The routine returns the full matrix of price effects, recovered from the elasticitymatrix, pre- and post-merger matrices of price-effect, $\mathbf{Q}_{0}$ and $\mathbf{Q}_{1}$, the vector of marginal production costs, $\mathbf{c}^{\left(n_{l}\right)}$, the vector of absolute CMCRs, $\triangle \mathbf{c}_{B}$, and, of course, the value of the $W F I_{B}$.

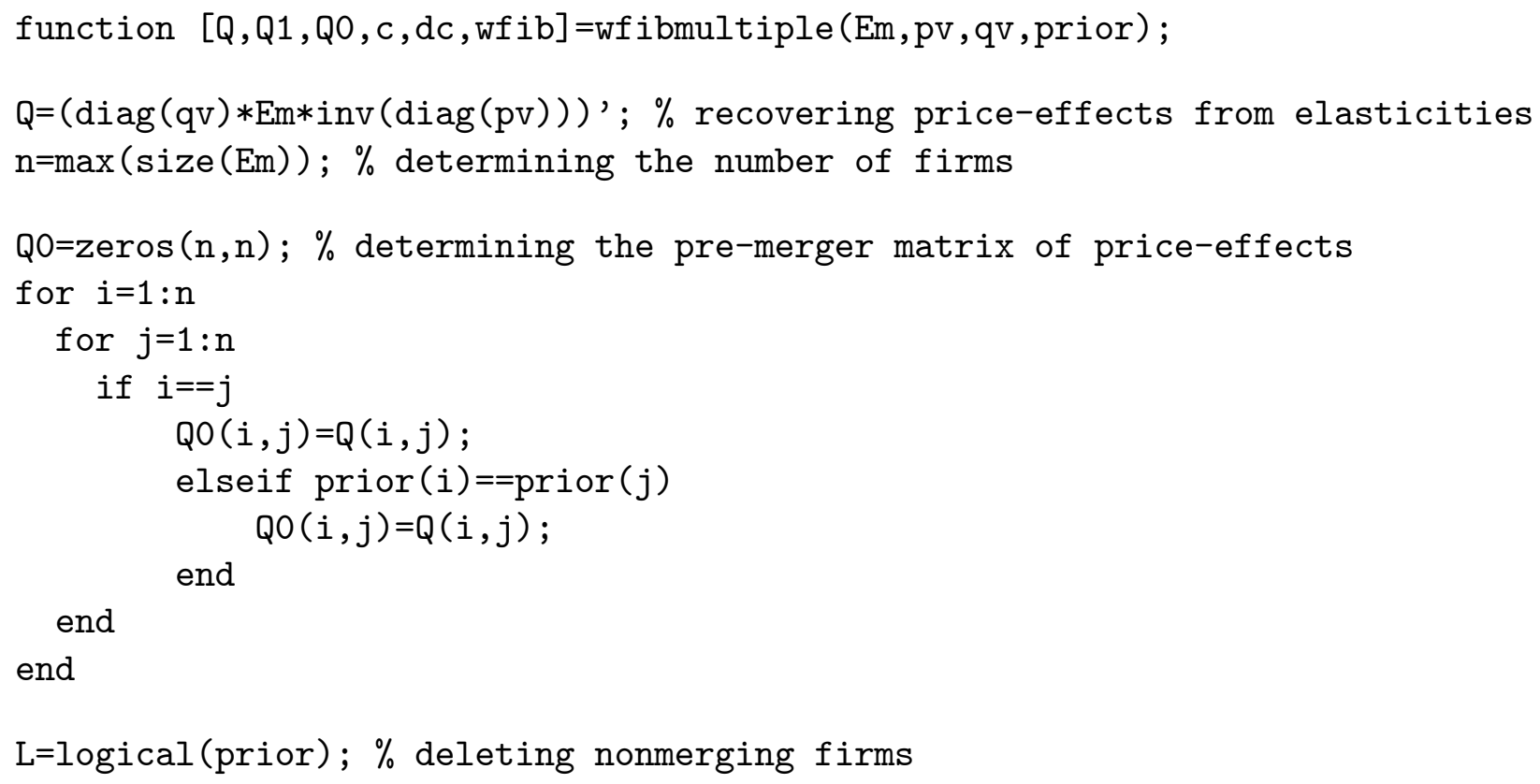

${ }^{33}$ See http://wfi.acle.nl for a user-friendly on-line version. 


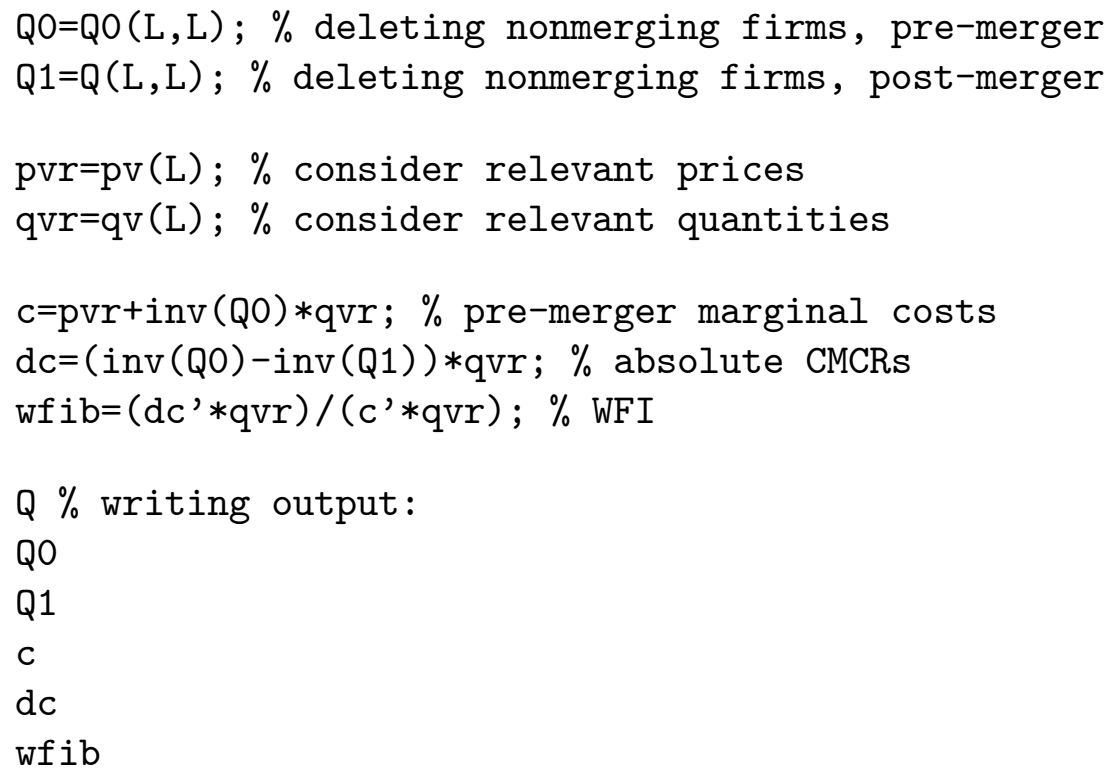

